\title{
A população refugiada no Brasil: em busca da proteção integral
}

\author{
Liliana Lyra Jubilut ${ }^{1}$ \\ Silvia Menicucci O. S. Apolinário²
}

\section{Resumo}

O Brasil é comumente apontado como um modelo de proteção à população refugiada na América do Sul, o que parece razoável ao se utilizarem os padrões mínimos estipulados pelo Direito Internacional dos Refugiados. Contudo, ao se pensar em uma proteção integral, que abranja as normas também provenientes do Direito Internacional dos Direitos Humanos, ainda há desafios a serem enfrentados. Este artigo pretende demonstrar quais são os desafios para uma proteção holística efetiva da dignidade humana da população refugiada no Brasil.

Palavras-chave: População refugiada. Refugiados. Brasil. Direitos Humanos. Proteção. Proteção Integral.

\footnotetext{
${ }^{1}$ Doutora e Mestre em Direito Internacional pela Universidade de São Paulo e tem LL.M em International Legal Studies pela New York University School of Law. É professora de Direito Internacional na Faculdade de Direito do Sul de Minas. É Consultora para a Criação do Conselho Brasileiro para Refugiados e foi advogada do Centro de Acolhida para Refugiados da Cáritas Arquidiocesana de São Paulo em parceria com o ACNUR e o governo brasileiro.

${ }^{2}$ Doutora e Mestre em Direito Internacional pela Universidade de São Paulo. É professora de Direito Internacional no curso de Relações Internacionais no UNICEUB, e coordenadora da Unidade Jurídica da Apex-Brasil. Foi advogada do Centro de Acolhida para Refugiados da Cáritas Arquidiocesana do Rio de Janeiro em parceria com o ACNUR e o governo brasileiro.
} 


\section{Introdução}

O Brasil é comumente apontado como um modelo de acolhida e proteção à população refugiada ${ }^{3}$ na América do $\mathrm{Sul}^{4}$, em função de ter uma lei a respeito do tema considerada avançada e de envolver órgãos governamentais, entidades da sociedade civil e órgãos da comunidade internacional.

Essa avaliação pode ser razoável ao se utilizarem como parâmetro de análise os padrões mínimos estipulados pelo Direito Internacional dos Refugiados, consagrados, sobretudo, na Convenção sobre o status de Refugiado de 1951 (Convenção de 51), no Protocolo sobre o status de Refugiado de 1967 (Protocolo de 67), e em instrumentos regionais, tais como a Declaração de Cartagena de 1984. Contudo, por ser a acolhida e a proteção da população refugiada partes integrantes da Proteção Internacional da Pessoa Humana ${ }^{5}$, fundada na dignidade humana ${ }^{6}$, verifica-se que se deve sempre buscar o aprimoramento, visando a uma proteção integral.

Partindo dessa premissa, o presente artigo tem como objetivo descrever a proteção e a acolhida à população refugiada no Brasil, a fim de verificar em quais aspectos ela pode e deve ser alterada, com vistas a que se obtenha a proteção integral, ou seja, aquela proteção que assegure não somente os direitos resguardados pelo Direito Internacional dos Refugiados, mas também os direitos humanos desses indivíduos, em consonância com o Direito Internacional dos Direitos Humanos e do próprio ordenamento jurídico brasileiro.

\footnotetext{
${ }^{3}$ Refere-se à "população refugiada" como o conjunto de pessoas que solicitaram refúgio e aguardam uma decisão a respeito de seu pedido (os solicitantes de refúgio) e as pessoas que já tiveram o seu status de refugiado reconhecidos (os refugiados).

${ }^{4}$ Para maiores detalhes relacionados ao tema, consultar: JUBILUT, 2006, p. 22-24 e FISCHEL; MARCOLINI, 2002, p. 37-39.

${ }^{5}$ Utiliza-se a expressão "Proteção Internacional da Pessoa Humana" como o conjunto das normas e valores assegurados pelo Direito Internacional dos Direitos Humanos, Direito Internacional dos Refugiados, Direito Internacional Humanitário e Direito Internacional Penal. Nesse sentido, busca-se referir ao conjunto mais amplo de regras emanadas da dignidade humana, e que visam a assegurar o cenário mais protetivo ao ser humano.

${ }^{6}$ Baseia-se aqui no ensinamento de Hannah Arendt pelo qual a dignidade humana é um dado, enquanto os direitos humanos são um construído a partir dela. Cf. LAFER, 1999, p. 134.
} 


\section{Aspectos históricos da acolhida e institucionalização da proteção da população refugiada no Brasil}

O Sistema Internacional Universal de Proteção à População Refugiada surgiu após a Segunda Guerra Mundial, e pode ser considerado como uma resposta direta às consequências desse conflito, no que respeita ao deslocamento de pessoas. Em 1950, foi criado, na forma de um órgão subsidiário da Assembléia Geral da Organização das Nações Unidas (ONU), o Alto Comissariado das Nações Unidas para Refugiados (ACNUR), que patrocinou a Convenção de 51 e o Protocolo de 67. Esses documentos internacionais universais estabelecem os padrões mínimos de proteção, cabendo aos Estados efetivá-los e, quando possível, ampliá-los.

Dessa feita, o comprometimento dos Estados e seu reflexo nos ordenamentos jurídicos internos para assegurar proteção à população refugiada são indispensáveis. No Brasil, não obstante sua limitação à formalidade, verifica-se a existência de certo engajamento estatal desde 1958, quando o país passou a integrar o Comitê Executivo do ACNUR, tendo na sequência, ratificado e incorporado tanto a Convenção de 51 quanto o Protocolo de $67^{7} .^{8}$

No final da década de 1970, o ACNUR estabeleceu um escritório ad hoc no Brasil. Todavia, somente em 1982, o governo brasileiro o reconheceu como um órgão internacional. A posição negativa do governo brasileiro por mais de uma década dificultou sobremaneira a atuação da comunidade internacional em prol da população refugiada. Nesse período em que se verificava o não reconhecimento, o Brasil (ainda não redemocratizado) servia apenas como território de passagem para refugiados latino-americanos. Não assegurava proteção ou permitia o estabelecimento deles em seu território. Durante essa fase, cerca de 20 mil argentinos, bolivianos, chilenos e uruguaios foram reassentados na Austrália, Canadá, Europa e Nova Zelândia9.

Desde o início da acolhida e proteção da população refugiada no Brasil, tem destaque o papel das entidades da sociedade civil, encarregadas de fazer o atendimento direto àquela. Além disso, verifica-se que, por meio da atuação dessas

\footnotetext{
${ }^{7}$ A Convenção de 51 foi recepcionada em 1961 e o Protocolo de 67 em 1972.

${ }^{8}$ Para maiores detalhes sobre a acolhida e proteção à população refugiada no Brasil, cf. JUBILUT, 2007.

${ }^{9}$ Cf. FISCHEL DE ANDRADE; MARCOLINI, 2002, p. 169.
} 
entidades, foi possível ampliar a proteção no Brasil, ainda que de maneira pontual e indireta, por exemplo, pela acolhida de 150 refugiados vietnamitas, alguns refugiados cubanos e 50 famílias Baha’i que foram recebidas, entre 1975 e 1980, e em 1986, respectivamente, como residentes estrangeiros ${ }^{10}$.

Em 1989 e 1990, na esteira da redemocratização, o Brasil ampliou seu comprometimento com o tema ao denunciar reservas que havia feito à Convenção de 51. No ano seguinte, foi adotada a Portaria Interministerial no 394 de 1991, que regulamentou o procedimento para o reconhecimento do status de refugiado. Tal procedimento envolvia formalmente a comunidade internacional, por meio da atuação do ACNUR, e o governo brasileiro. E contava também com a participação da sociedade civil que continuava fazendo o atendimento direto à população refugiada ${ }^{11}$.

Em 1992, o Brasil, inspirado pela Declaração de Cartagena, instrumento adotado no âmbito interamericano, começou a adotar a grave e generalizada violação de direitos humanos como critério para o reconhecimento do status de refugiado $^{12}$, o que permitiu a proteção a angolanos que fugiam da guerra civil em seu país, e que constituem até os dias atuais a maior percentagem de refugiados, em termos de nacionalidade, em território brasileiro.

Seguindo na tradição de ampliar a proteção e acolhida à população refugiada, verificada desde a redemocratização, foi aprovada a Lei n 9.474 , de 22 de julho de 1997, que definiu os mecanismos para implementação da Convenção de 1951 e que tratou de temas correlatos, sendo, desde então, a legislação interna a respeito da proteção da população refugiada.

${ }^{10}$ Cf. JUBILUT, 2007, p. 173.

11 "Em linhas gerais o procedimento para a concessão de refúgio ocorria da seguinte maneira: o ACNUR realizava uma entrevista com os solicitantes de refúgio e com base nela elaborava um parecer recomendando ou não a concessão de refúgio naquele caso. Esse parecer era encaminhado ao Ministério das Relações Exteriores, que se pronunciava sobre isso e fazia sua remessa ao Ministério da Justiça, que proferia a decisão final". (JUBILUT, 2007, p. 175).

${ }^{12}$ A grave e generalizada violação de direitos humanos foi consagrada normativamente no art. $1^{\circ}$, inciso III da Lei no 9.474/97. Ao ser aplicada, ela transfere o foco da análise da solicitação do refúgio da perseguição individual para a situação objetiva do país de origem do solicitante. 


\section{A proteção da população refugiada no Brasil: procedimentos de determinação do status de refugiado e reassentamento}

A Lei no 9.474/97 se tornou um marco da proteção à população refugiada no Brasil e consolidou mudanças significativas também na acolhida à população refugiada, positivando direitos e deveres tanto dos indivíduos quanto do Estado brasileiro.

Com base nesse diploma legal, verifica-se que a proteção e a acolhida à população refugiada pode ocorrer no Brasil de duas maneiras: 1) quando o Brasil é o primeiro país de acolhida e proteção, ou seja, quando a determinação do status de refugiado é realizada pelo governo brasileiro ou 2) quando o Brasil acolhe refugiados já reconhecidos como tais por outros Estados ou pelo ACNUR ${ }^{13}$, por meio do reassentamento. Como os procedimentos em cada situação são distintos, optou-se por separá-los em duas seções que serão analisadas na sequência.

\subsection{O Brasil como primeiro país de acolhida e proteção}

A maior parte dos refugiados no Brasil ${ }^{14}$ teve o país como seu primeiro local de acolhida. Isso significa que no Brasil foi realizada a determinação do status de refugiado, e que a situação do solicitante pode ser enquadrada nos critérios legais (tanto internacionais quanto nacionais), existentes para o reconhecimento da condição de refugiado.

De acordo com a Convenção de 51, para que uma pessoa seja reconhecida como refugiada ela deve: 1) ter bem-fundado temor de perseguição; 2) em função de sua raça, religião, nacionalidade, opinião política ou pertencimento a grupo social; 3) deve carecer da proteção internacional, o que significa que a situação objetiva de seu país de origem ou residência habitual deve ensejar a necessidade de proteção internacional, ou seja, a pessoa não pode estar incluída nas cláusulas de

\footnotetext{
${ }^{13}$ Em função de previsão em seu estatuto, o ACNUR pode reconhecer refugiados "sob mandato".

${ }^{14}$ Dos 3956 refugiados no Brasil, 3579 tiveram seu status reconhecido originariamente no Brasil e 377 vieram reassentados, o que faz com que aqueles componham mais de $90 \%$ do total. Dados atualizados até 14 de janeiro de 2009 e obtidos em consulta ao Comitê Nacional para Refugiados (CONARE).
} 
cessação; e 4) deve merecer a proteção internacional, ou seja, não pode ter agido de maneira contrária ao Direito Internacional e, portanto, não pode se enquadrar nas cláusulas de exclusão que incluem cometimento de crimes de guerra, crimes contra humanidade ou crimes contra a paz, cometimento de grave crime de delito comum ou cometimento de atos contrários aos princípios e propósitos da ONU.

Além desses requisitos, a Convenção de 51 permitia que os Estados optassem por somente reconhecer como refugiadas as pessoas que preenchessem todas as condições em função de eventos ocorridos na Europa antes de $1^{\circ}$ de janeiro de 1951. Tais possibilidades ficaram conhecidas como reserva geográfica e reserva temporal.

A inclusão de tais reservas denota o constante entendimento por parte dos Estados de que a temática dos refúgios é pontual: como a Convenção de 51 tem como principal objeto a população refugiada decorrentes da Segunda Guerra Mundial, os Estados acharam que poderiam limitar a definição para abranger tão somente esse grupo. Tal entendimento, contudo, se provou equivocado.

Em função do contínuo aparecimento de refugiados, foi celebrado o Protocolo de 67 com a função específica de remover as reservas geográfica e temporal, permitidas pela Convenção de 51. Dessa feita, a melhor proteção internacional universal é a que aplica a Convenção de 51 revisada pelo Protocolo de 67.

O Brasil, ao adotar a Lei $n^{\circ}$ 9.474/94 incorporou, de maneira geral, as regras do sistema internacional universal em sua definição, optando também, como mencionado, em ampliar a proteção ao incluir a grave e generalizada violação de direitos humanos como motivo para o reconhecimento do status de refugiado ${ }^{15}$.

Além de estabelecer a definição de refugiado a ser aplicada no Brasil, a Lei no 9.474/97 estabeleceu as bases do procedimento administrativo para a determinação do status de refugiado.

A primeira inovação neste sentido vem a ser a criação de um órgão de deliberação coletiva, no âmbito do Ministério da Justiça, o Comitê Nacional para Refugiados (CONARE) ${ }^{16}$, com competência para: analisar o pedido e de-

\footnotetext{
${ }^{15}$ A respeito do tema e, sobretudo, das diferenças entre a definição brasileira e a definição internacional universal, cf. JUBILUT, 2006, p. 31 et seq.

${ }^{16} \mathrm{O}$ Regimento Interno do Comitê Nacional para os Refugiados pode ser consultado em: BARBOSA; HORA, 2007, p. 148-152.
} 
clarar o reconhecimento, em primeira instância, da condição de refugiado; decidir a cessação, em primeira instância, ex officio ou mediante requerimento das autoridades competentes, da condição de refugiado; determinar a perda, em primeira instância, da condição de refugiado ${ }^{17}$; orientar e coordenar as ações necessárias à eficácia da proteção, assistência e apoio jurídico à população refugiada; e aprovar instruções normativas esclarecedoras à execução da Lei ${ }^{\circ}$ 9.474/97.

Cada uma das seguintes entidades tem um representante, que reunidos, compõem o CONARE ${ }^{18}$ : Ministério da Justiça, que o preside, Ministério das Relações Exteriores, Ministério do Trabalho, Ministério da Saúde, Ministério da Educação e do Desporto, Departamento de Polícia Federal e uma organização não-governamental, que se dedique a atividades de assistência e proteção da população refugiada no País, sendo esta atualmente a Cáritas Arquidiocesana de São Paulo. O ACNUR é membro convidado para as reuniões do CONARE, com direito a voz, contudo, sem direito a voto.

O Coordenador-Geral do CONARE é responsável por preparar os processos de requerimento de refúgio e a pauta de reunião, sendo que o CONARE pode reunir-se com quórum de quatro membros com direito a voto, deliberando por maioria simples. Em caso de empate, será considerado voto decisivo o do Presidente do CONARE. Assim, na prática, definida a pauta de reunião, o chamado grupo de estudos prévios (formado pelo Coordenador-Geral do CONARE, representantes do ACNUR, do Ministério das Relações Exteriores, da Polícia Federal e da sociedade civil) se reúne para apreciar as solicitações de refúgio, de forma a agilizar o processo decisório efetivo na

${ }^{17} \mathrm{O}$ art. 39, inciso IV da Lei $\mathrm{n}^{\circ}$ 9.474/97 determina que a saída do território nacional sem prévia autorização do Governo Brasil implicará a perda da condição de refugiado, além das outras possibilidades, a saber: a renúncia, a prova da falsidade dos fundamentos invocados para o reconhecimento da condição de refugiado ou a existência de fatos que, se fossem conhecidos quando do reconhecimento, teriam ensejado uma decisão negativa, e o exercício de atividades contrárias à segurança nacional ou à ordem pública. $\mathrm{O}$ caso da saída sem prévia autorização do governo brasileiro foi objeto da Resolução Normativa do CONARE $n^{\circ}$ 5, de 11 de março de 1999, posteriormente revogada pela Resolução Normativa $\mathrm{n}^{\circ} 12$, de 29 de abril de 2005 , que dispõe a respeito da autorização para viagem de refugiado ao exterior, a emissão de passaporte brasileiro para estrangeiro refugiado, quando necessário, bem como o processo de perda da condição de refugiado em razão de sua saída de forma desautorizada.

${ }^{18}$ Os representantes mencionados são designados pelo Presidente da República, mediante indicações dos órgãos e da entidade que o compõem. (Lei n 9.474/97, art. 14, $\$ 2^{\circ}$ ). 
reunião plenária em que formalmente se reconhece o status de refugiado ou se indefere a solicitação ${ }^{19}$.

Da participação direta da sociedade civil no CONARE e da participação do ACNUR no mesmo órgão, depreende-se o caráter tripartite da determinação do status de refugiado no Brasil, o que vem a ser uma segunda inovação em termos procedimentais, e que busca assegurar um caráter mais holístico da proteção uma vez que a acolhida é feita pelo Brasil como um todo e não apenas pelo governo brasileiro. Tal caráter é verificado não somente no momento da decisão, como também durante todo o procedimento e acolhida da população refugiada no Brasil.

Em linhas gerais, o procedimento do processo de reconhecimento da condição de refugiado inicia-se com a apresentação do estrangeiro perante a autoridade competente - órgão da Polícia Federal mais próximo de onde ele se encontre - para externar sua vontade de solicitar o reconhecimento da condição de refugiado. $\mathrm{O}$ processo é gratuito e tem caráter urgente. O Termo de Declarações, então lavrado, marca formalmente o estabelecimento dos procedimentos. Deve-se ressaltar que o ingresso irregular no território nacional não constitui impedimento para a solicitação de refúgio ${ }^{20}$. O ACNUR deverá ser informado a respeito da solicitação de refúgio e poderá oferecer sugestões visando facilitar seu andamento ${ }^{21}$.

O estrangeiro presta, assim, declarações a respeito das circunstâncias de sua entrada no Brasil e das razões que o fizeram deixar seu país de origem e/ou residência habitual, além de preencher, com a ajuda de um intérprete se houver necessidade, a solicitação de reconhecimento como refugiado, indicando identificação completa, qualificação profissional, grau de escolaridade do solicitante e membros de seu grupo familiar, bem como o relato das circunstâncias e dos fatos que fundamentam o pedido de refúgio, inclusive com indicação de elementos de prova pertinentes.

\footnotetext{
${ }^{19}$ A atuação do CONARE pode ser analisada em: LEAO, 2007, p. 148-152.

${ }^{20}$ Cf. art. 8 da Lei $n^{\circ} 9.474 / 97$.

${ }^{21}$ Cf. art. 18 parágrafo único da Lei ${ }^{\circ} 9.474 / 97$.
} 
Consta na Lei ${ }^{\circ}$ 9.474/97 que o registro da declaração ${ }^{22}$ e a supervisão do preenchimento da solicitação de refúgio devem ser efetuados por funcionários qualificados e em condições que garantam o sigilo das informações. Na prática, haverá diferença caso o processo se inicie perante a Polícia Federal no Rio de Janeiro ou em São Paulo ou nas demais cidades do país, visto que naquelas cidades ficam as sedes da Cáritas Arquidiocesana do Rio de Janeiro e da Cáritas Arquidiocesana de São Paulo ${ }^{23}$, que auxiliam o solicitante durante o processo, nos Centros de Acolhida para Refugiados. Assim, estando o solicitante de refúgio nas proximidades dos Centros de Acolhida, a tendência é de um apoio mais efetivo. A fim de corrigir tal situação, as Cáritas Arquidiocesanas do Rio de Janeiro e de São Paulo e o ACNUR buscam construir e ampliar uma rede de solidariedade, envolvendo entidades fora do eixo Rio-São Paulo, para que os solicitantes de refúgio tenham apoio onde quer que se localizem no Brasil.

Após o recebimento da solicitação de refúgio e mediante apresentação de declaração do CONARE, o Departamento de Polícia Federal emite um protocolo em favor do solicitante e de seu grupo familiar que se encontre no território nacional, sendo que serão averbados no protocolo do solicitante de refúgio responsável os menores de catorze $\operatorname{anos}^{24}$. Esse protocolo autoriza a estada do solicitante e seus familiares até a de-

${ }^{22}$ A Resolução Normativa do CONARE no 1, de 27 de outubro de 1998, estabeleceu o modelo para o Termo de Declaração a ser preenchido pelo Departamento de Polícia Federal por ocasião da solicitação inicial de refúgio. A resolução determina que o referido termo deva ser encaminhado à Coordenadoria Geral do CONARE, com cópia à respectiva Cáritas Arquidiocesana, visando ao preenchimento do questionário que possibilitará a apreciação do pedido.

${ }^{23}$ A Resolução Normativa do CONARE n 2, de 27 de outubro de 1998, adotou o modelo de questionário a ser preenchido pelo solicitante de refúgio. A resolução determina que o referido questionário seja preenchido na sede da respectiva Cáritas Arquidiocesana e, posteriormente, encaminhado à Coordenadoria Geral do CONARE para os procedimentos pertinentes, ou seja, a emissão de uma declaração, atestando que o estrangeiro solicitou refúgio, permitindo a ele a obtenção do protocolo a ser emitido pelo Departamento de Polícia Federal. Estabeleceu a Resolução ainda, após modificações introduzidas pela Resolução Normativa do CONARE no 9, de 6 de agosto de 2002, que, nas circunscrições onde não houver sede da Cáritas Arquidiocesana, o preenchimento deverá ser feito no Departamento de Polícia Federal e encaminhado juntamente com o termo de declarações.

${ }^{24}$ A Resolução Normativa do CONARE no 6, de 26 de maio de 1999, dispôs a respeito da concessão do protocolo ao solicitante de refúgio. Fica estabelecido que o Departamento de Polícia Federal emitirá o protocolo em favor do solicitante de refúgio e de seu grupo familiar que se encontre em território nacional, mediante a apresentação de declaração a ser fornecida pela Coordenação-Geral do CONARE. O prazo de validade do protocolo é de noventa dias, prorrogável por igual período, até a decisão final do processo. 
cisão final do processo. Com base nesse protocolo e observando seu prazo de validade, o Ministério de Trabalho expedirá a carteira de trabalho provisória para o exercício de atividades remuneradas no País, mediante demanda do próprio estrangeiro.

Enquanto estiver pendente o processo relativo à solicitação de refúgio, aos solicitantes será aplicável a legislação a respeito de estrangeiros - a Lei ${ }^{\circ}{ }^{\circ} 6.815$, de 19 de agosto de 1980 (Estatuto do Estrangeiro) -, respeitadas as disposições específicas previstas na Lei ${ }^{\circ}$ 9.474/97. Interessante ressaltar que a solicitação de refúgio suspende, até decisão definitiva, qualquer processo de extradição pendente, baseado nos fatos que fundamentaram o reconhecimento do status de refúgio, assim como qualquer procedimento administrativo ou criminal pela entrada irregular ${ }^{25}$. Portanto, a solicitação deve ser comunicada ao órgão em que tramita o processo ou procedimento.

Na continuação, a autoridade competente deve proceder a diligências requeridas pelo CONARE, devendo averiguar os fatos cujo conhecimento seja conveniente para uma justa e rápida decisão, com respeito ao princípio da confidencialidade. Após a instrução, a autoridade competente elabora relatório que é enviado ao Coordenador-Geral do CONARE, para inclusão na pauta da próxima reunião. Caso o solicitante não dê seguimento no prazo máximo de seis meses a quaisquer dos procedimentos legais que objetivem a decisão final do pedido ou não atenda às convocações que lhe forem dirigidas, sua solicitação de refúgio será passível de indeferimento pelo CONARE. O indeferimento será publicado no Diário Oficial da União ${ }^{26}$.

Quaisquer intervenientes nos processos relativos às solicitações de refúgio devem guardar segredo profissional quanto às informações a que terão acesso no exercício de suas funções.

${ }^{25}$ Cf. Arts. 10 e 34 da Lei $n^{\circ}$ 9.474/97.

${ }^{26}$ A Resolução Normativa do CONARE n 7, de 6 de agosto de 2002, veio regular a adoção de procedimentos e atendimento a convocações, tendo sido revogada pela Resolução Normativo do CONARE no 11 , de 29 de abril de 2005, que teve como objetivo dispor a respeito da publicação da notificação prevista no art. 29 da Lei 9.474/97, ou seja, estabelecer o início da contagem do prazo recursal, quando o interessado não for localizado. A Resolução estabeleceu que será passível de indeferimento pelo CONARE, sem análise de mérito, a solicitação de reconhecimento da condição de refugiado daquele que não der seguimento, no prazo máximo de seis meses, a quaisquer dos procedimentos legais que objetivem a decisão final do pedido ou não atender às convocações que lhe forem dirigidas. 
O art. 26 da Lei n ${ }^{\circ}$ 9.474/97 é de extrema relevância ao afirmar que a decisão pelo reconhecimento da condição de refugiado é considerada um ato declaratório e deve estar devidamente fundamentada. Proferida a decisão, o CONARE notifica o solicitante e o Departamento de Polícia Federal para as medidas administrativas cabíveis. No caso de decisão positiva, o refugiado é registrado junto ao Departamento de Polícia Federal, devendo assinar Termo de Responsabilidade ${ }^{27}$ e solicitar cédula de identidade pertinente, a qual indica seu status de modo expresso.

O reconhecimento da condição de refugiado obsta o seguimento de qualquer pedido de extradição, baseado nos fatos que fundamentam o reconhecimento do status de refugiado ${ }^{28}$. Também não poderá ser expulso do território nacional o refugiado que esteja regularmente registrado, salvo por motivos de segurança nacional ou de ordem pública. Caso a expulsão venha a se verificar, ela não poderá ser feita para país em que a vida, a liberdade ou a integridade física do refugiado possam estar em risco, e apenas poderá ser feita quando houver certeza de sua admissão em país onde não haja riscos de perseguição. O reconhecimento da condição de refugiado também implica o arquivamento dos processos e procedimentos administrativos ou criminais, decorrentes da entrada irregular no Brasil.

A decisão negativa deve também estar fundamentada na notificação ao solicitante ${ }^{29}$, cabendo direito de recurso ao Ministro da Justiça, no prazo de quinze dias, contados do recebimento da notificação. Durante a avaliação do recurso, o solicitante e seus familiares poderão permanecer em território nacional.

${ }^{27}$ A Resolução Normativa do CONARE nº 3, de 27 de outubro de 1998, estabeleceu o modelo de Termo de Responsabilidade que deve preceder o registro, na condição de refugiado, no Departamento de Polícia Federal. Há previsão de que a autoridade competente deverá utilizar a ajuda de intérprete nos casos em que o requerente não domine o idioma português, visando a possibilitar a plena ciência do conteúdo do termo.

${ }^{28}$ O Supremo Tribunal Federal votou pela constitucionalidade da Lei no 9.474/97 no que se refere à possibilidade de o reconhecimento do status de refugiado obstar a extradição, justificando tal postura por entender que como o refúgio e a extradição são de competência do Executivo no Brasil não haveria violação da separação de poderes. Cf. BRASIL, $2001 \mathrm{e}$ BRASIL, 2007.

${ }^{29}$ A Resolução Normativa no 8 , de 6 de agosto de 2002, dispôs a respeito da notificação de indeferimento do pedido de reconhecimento da condição de refugiado. Assim, ficou determinado que seja publicado no Diário Oficial o indeferimento do pedido de reconhecimento da condição de refugiado daquele solicitante que no prazo de seis meses, a contar da data da decisão do CONARE, não for localizado para receber a devida notificação. 
A decisão do Ministro da Justiça não será passível de recurso dentro do processo administrativo, devendo ser notificada ao CONARE, para ciência do solicitante, e ao Departamento de Polícia Federal, para as providências cabíveis. Havendo a recusa definitiva do reconhecimento do status de refugiado, o solicitante ficará sujeito à legislação de estrangeiros, não devendo ocorrer sua transferência ao seu país de nacionalidade ou residência habitual, enquanto permanecerem as circunstâncias que coloquem em risco sua vida, integridade física e liberdade, salvo no caso em que tenha cometido crime contra a paz, crime de guerra, crime contra a humanidade, crime hediondo, participado de atos terroristas ou tráfico de drogas, ou seja, considerado culpado de atos contrários aos fins e princípios da ONU.

Não obstante a negativa no processo administrativo, entende-se que o acesso à justiça é garantido a todas as pessoas em território brasileiro. Logo, poderá haver a busca do Judiciário para analisar se a decisão estava em conformidade com os preceitos da Lei $\mathrm{n}^{\circ}$ 9.474/97, pois, sendo o reconhecimento do status de refugiado um ato declaratório e não constitutivo pode haver violação de um direito do solicitante com recusa do pedido.

Além do procedimento acima descrito, há ainda a possibilidade de extensão da condição de refugiado ao cônjuge, aos ascendentes e descendentes, assim como aos demais membros do grupo familiar que do refugiado dependerem economicamente, desde que se encontrem em território nacional. Os estrangeiros devem assim buscar o Departamento de Polícia Federal para formalizar a solicitação de refúgio, mediante Termo de Declaração, quando seus familiares chegarem ao Brasil.

A Resolução Normativa do CONARE no 4, de 11 de março de 1999, determinou que poderão ser estendidos os efeitos da condição de refugiado a título de reunião familiar, considerando como dependentes: o cônjuge; os(as) filhos(as) solteiros(as) menores de 21 anos, naturais ou adotivos, ou maiores quando não puderem prover o próprio sustento; ascendentes e irmãos, netos, bisnetos ou sobrinhos, se órfãos, solteiros e menores de 21 anos, ou de qualquer idade quando não puderem prover o próprio sustento $^{30}$. Considera-se equiparado ao órfão o menor cujos pais encontrem-se presos ou desaparecidos. Em anexo à referida Resolução, encontra-se o Termo de Solicitação para Reunião Familiar.

\footnotetext{
${ }^{30}$ A avaliação da condição de dependentes que não podem prover o próprio sustento atenderá a critérios de ordem física e mental e deverá ser declarada por médico.
} 
Por fim, há ainda um mecanismo incipiente de proteção temporária, estabelecido pela Resolução do CONARE n. 13, de 23 de março de 2007, que dispõe a respeito da referência de situações especiais pelo CONARE ao Conselho Nacional de Imigração (CNI). De acordo com esta resolução, os casos de solicitação de refúgio que não cumpram com os requisitos de elegibilidade da Lei $n^{\circ}$ 9.474/97 podem ser analisados pelo CNI para concessão de permanência, baseando-se em condições humanitárias. Não se trata, portanto, de um mecanismo que pode ser solicitado pelo próprio estrangeiro, demandando a iniciativa do próprio CONARE.

\subsection{O Brasil como país de reassentamento}

O sistema internacional de proteção à população refugiada se baseia em três "soluções duráveis": 1) a integração local; 2) a repatriação; e 3) o reassentamento.

A integração local vem a ser a "adaptação do refugiado à sociedade do país que o acolheu e lhe concedeu refúgio" (JUBILUT, 2007, p. 154). Nesse particular, o ordenamento brasileiro dispôs a respeito da possibilidade de obtenção de permanência definitiva pelo refugiado. A Resolução Normativa do CNI, de 21 de agosto de 1997, dispõe que o Ministério da Justiça, resguardados os interesses nacionais, poderá conceder a permanência definitiva ao estrangeiro detentor da condição de refugiado ou asilado, que comprovadamente, preencher um dos seguintes requisitos: 1) residir no Brasil há no mínimo seis anos na condição de refugiado ou asilado; 2) ser profissional qualificado e contratado por instituição instalada no país, ouvido o Ministério do Trabalho; 3) ser profissional de capacitação reconhecida por órgão da área pertinente; e 4) estar estabelecido com negócio resultante de investimento de capital próprio que satisfaça os objetivos de resolução normativa do CNI relativos à concessão de visto a investidor estrangeiro ${ }^{31}$. A possibilidade de naturalização, por sua vez, subordina-se aos preceitos existentes na Constituição Brasileira e no Estatuto do Estrangeiro ${ }^{32}$.

${ }^{31}$ A Resolução Normativa do CONARE n 10, de 22 de setembro de 2003, veio dispor a respeito da situação dos refugiados detentores de permanência definitiva, estabelecendo que a permanência não acarreta a cessão ou a perda da condição de refugiado, assim como outras disposições a respeito da expedição do documento de identidade e emissão de passaporte brasileiro ao refugiado em situação permanente.

$32 \mathrm{O}$ art. 34 da Convenção de 51 determina que os Estados facilitem, na medida do possível, a assimilação e a naturalização dos refugiados, esforçando-se notadamente para acelerar o processo de naturalização e reduzir, na medida do possível, as taxas e despesas desse processo. 
A repatriação vem a ser o retorno do refugiado ao seu país de origem ou de residência habitual, uma vez cessados os riscos à sua vida, segurança, liberdade ou integridade física, ou seja, uma vez cessados os riscos de perseguição.

Já o reassentamento, conforme explica Liliana Jubilut:

pode ser entendido de duas maneiras: no início da atuação do ACNUR era a prática de se transferirem refugiados de um Estado para outro, podendo ser inclusive de seu Estado de origem diretamente para o Estado de acolhida, ou seja, era a efetiva transferência de um refugiado para um Estado de asilo; modernamente vem a ser a transferência de indivíduos, já reconhecidos como refugiados, mas que não se adaptaram ao país de acolhida (denominado também de país de asilo ou ainda de primeiro país), para outro Estado, o qual é denominado terceiro país, que se entende mais adequado às necessidades desses indivíduos. (JUBILUT, 2007, p. 154).

O ACNUR funciona como o interlocutor no processo de reassentamento, tentando assegurar as necessidades dos indivíduos e buscando a necessária cooperação de Estados que aceitem receber refugiados reassentados, uma vez que o reassentamento não é um direito do indivíduo.

O Brasil aceitou o desafio de ser um país de reassentamento em 1999, quando celebrou com o ACNUR o Acordo Marco para o Reassentamento de Refugiados, baseando-se no artigo 46 da Lei $n^{\circ} 9.474 / 97$. Desde então, o projeto de reassentamento no Brasil tem sido efetivado ${ }^{33}$.

O primeiro grupo de refugiados reassentados no Brasil foi composto de afegãos que chegaram ao Brasil em 2002 e foram recebidos em Porto Alegre. Quase a metade dos chegados retornou ao Afeganistão em 2003 por livre escolha, e o projeto piloto foi analisado positivamente.

Em 2004, teve início uma nova fase do reassentamento no Brasil, quando, nas comemorações do aniversário da Declaração de Cartagena, o Brasil propôs a ideia de reassentamento solidário, que constitui uma abordagem humanitária de reassentamento com um enfoque regional. A proposta seria a de auxiliar Estados da região em que houvesse grande número de refugiados provenientes do conflito colombiano, e selecioná-los a partir de critérios humanitários.

\footnotetext{
${ }^{33}$ Para maiores detalhes sobre o reassentamento no Brasil, cf. JUBILUT, 2007, p. 199 et seq.
} 
Tal proposta passou a integrar a iniciativa regional da Declaração e do Plano de Ação do México para Fortalecer a Proteção Internacional dos Refugiados na América Latina $^{34}$ e a pautar o reassentamento no Brasil. E com ela, houve uma ampliação do número de refugiados reassentados recebidos e das entidades envolvidas na acolhida deles em parceira com o ACNUR e com o governo brasileiro. Atualmente há três entidades que atuam com refugiados reassentados no Brasil: a Associação Antônio Vieira (no Rio Grande do Sul), a Cáritas Brasileira - Regional São Paulo (em São Paulo) e o Centro de Direitos Humanos e Memória Popular (no Rio Grande do Norte) ${ }^{35}$.

Em 2008, verificou-se uma nova modificação no projeto inicial, com a acolhida de um grupo de palestinos, considerado grande em termos de Brasil. O reassentamento dos palestinos demonstrou que, apesar do foco regional proposto pelo reassentamento solidário, o projeto brasileiro segue atento e solidário aos desafios universais e tem buscado acolher refugiados que precisem de proteção internacional, cumprindo, assim, com suas responsabilidades humanitárias.

\section{A busca da proteção integral da população refugiada no Brasil}

Tendo-se verificado o histórico e as características atuais da acolhida e proteção da população refugiada no Brasil nos itens anteriores, passa-se agora a analisar como elas podem ser aprofundadas, a fim de que se possa atingir a proteção integral à população refugiada no Brasil.

\subsection{O Direito Internacional dos Refugiados como vertente da proteção internacional da pessoa humana}

A doutrina identifica três vertentes da proteção internacional da pessoa humana: o Direito Internacional dos Direitos Humanos, o Direito

\footnotetext{
${ }^{34}$ Adotados durante a Reunião Comemorativa do Vigésimo Aniversário da Declaração de Cartagena sobre Refugiados, realizada na Cidade do México, México, nos dias 15 e 16 de Novembro de 2004.

${ }^{35}$ Além das duas parceiras na acolhida das pessoas que pedem refúgio no Brasil (Cáritas Arquidiocesana do Rio de Janeiro e Cáritas Arquidiocesana de São Paulo) e das três parceiras de reassentamento, o Instituto Migrações e Direitos Humanos também é parceiro do ACNUR e do governo brasileiro na proteção e acolhida aos refugiados no Brasil.
} 
Internacional Humanitário e o Direito Internacional dos Refugiados. De uma visão compartimentalizada, pautada nas origens históricas diversas, a doutrina e a prática internacional estão caminhando para a interação normativa desses três ramos do Direito Internacional Público, apesar de suas diferenças quanto aos meios de implementação, supervisão ou controle em determinadas circunstâncias ${ }^{36}$. Assim, fica cada vez mais difícil negar a complementaridade entre as vertentes mencionadas, as quais são guiadas por um mesmo propósito - a proteção da pessoa humana em todas e quaisquer circunstâncias.

As causas que motivam a solicitação de refúgio constituem, em sua essência, violações a direitos humanos consagrados internacionalmente em tratados, sobretudo em função de seu status civil e político. Em âmbito americano, a Declaração de Cartagena de 1984 reafirma esse entendimento ao estabelecer na terceira conclusão, mediante referência à Convenção da OUA e à doutrina utilizada nos relatórios da Comissão Interamericana de Direitos Humanos, que a definição ou o conceito de refugiado recomendável para utilização na região é o que, para além de conter os elementos da Convenção de 51 e do Protocolo de 67, considere também como refugiados:

[...] as pessoas que tenham fugido de seus países porque a sua vida, segurança ou liberdade tenham sido ameaçadas pela violência generalizada, a agressão estrangeira, os conflitos internos, a violação maciça dos direitos humanos ou outras circunstâncias que tenham perturbado gravemente a ordem pública.

Do mesmo modo, o próprio processo de solicitação de refúgio ocorre em face do Estado, e deve assim observar as garantias do devido processo, previstas nos instrumentos de direitos humanos. Sendo reconhecida ou não a condição de refugiado, o estrangeiro não deixa de ser sujeito de direitos humanos, devendo ser respeitado em sua dignidade. Desse modo, antes, durante e depois da solicitação de refúgio, o estrangeiro não pode ser privado dos direitos humanos - civis, políticos, econômicos, sociais e culturais - a que tem direito, nos termos estabelecidos pelo Direito Internacional, por sua condição humana.

Nessa perspectiva, o art. 48 da Lei no 9.474/97 é de extrema importância quando dispõe que:

\footnotetext{
${ }^{36}$ Cf. TRINDADE; PEYTRIGNET; SANTIAGO, 2004 e JUBILUT, 2007, p. 51 et seq.
} 
Os preceitos desta Lei deverão ser interpretados em harmonia com a Declaração Universal dos Direitos do Homem de 1948, com a Convenção sobre o Estatuto dos Refugiados de 1951, com o Protocolo sobre o Estatuto dos Refugiados de 1967 e com todo dispositivo pertinente de instrumento internacional de proteção de direitos humanos com o qual o Governo brasileiro estiver comprometido.

É expressa, portanto, a obrigação de que o refúgio em âmbito brasileiro seja considerado a partir da proteção internacional dos direitos humanos, em consonância com todos os tratados de direitos humanos ratificados pelo Estado brasileiro e com as normas internas relativas a esses direitos, pois somente assim se poderá falar em proteção integral à população refugiada no Brasil.

No que concerne à relação entre o internacional e o interno, e à aceitação pelo Estado brasileiro da jurisdição da Corte Interamericana de Direitos Humanos, cumpre mencionar que o Sistema Interamericano de Direitos Humanos é rico em jurisprudência relevante à proteção da população refugiada, demonstrando a relação entre o Direito Internacional dos Refugiados e o Direito Internacional dos Direitos Humanos ${ }^{37}$.

No caso Tribunal Constitucional vs $\mathrm{Peru}^{38}$, por exemplo, a Corte Interamericana de Direitos Humanos declarou que o elenco de garantias mínimas do devido Processo (art. 8.2. da Convenção Americana) deve ser respeitado em qualquer tipo de ato estatal concernente à determinação dos direitos dos indivíduos ${ }^{39}$ e não se restringe somente a procedimentos de caráter penal, o que se explica, pois, a sua aplicação no procedimento para a determinação da condição de refugiado.

É importante destacar que, em termos de relacionamento entre a proteção à população refugiada e os direitos humanos, não basta voltar-se apenas ao procedimento de reconhecimento do status de refugiado, sendo necessário que o vínculo também exista no momento da solução duradoura (repatriação voluntaria, integração local, reassentamento) e garanta o respeito a todos os direitos próprios do ser humano e não somente dos direitos assegurados aos refugiados.

\footnotetext{
${ }^{37}$ Cf. CORTE INTERAMERICANA DE DERECHOS HUMANOS, 2007 e COMISION INTERAMERICANA DE DERECHOS HUMANOS, 2006.

${ }^{38}$ CORTE INTERAMERICANA DE DERECHOS HUMANOS, 2001.

${ }^{39} \mathrm{O}$ art. 14, I da Declaração Universal de Direitos Humanos de 1948 estabelece que "Todo homem, vitima de perseguição, tem o direito de procurar e de gozar de asilo em outros países".
} 
Em função disso, a análise da proteção integral à população refugiada no Brasil será feita nos dois próximos itens, considerando inicialmente o procedimento para a determinação do status de refugiado e, posteriormente, considerando principalmente os direitos econômicos, sociais e culturais, cuja realização é fator crítico no momento da solução duradoura, exigindo o planejamento e a execução de políticas públicas específicas aos refugiados.

\subsection{0 procedimento para a determinação da condição de refugiado no Brasil e os direitos humanos}

A análise do procedimento para determinação do status de refugiado no Brasil, descrito neste artigo, a partir da ótica da proteção internacional da pessoa humana, permite a identificação de algumas questões de especial importância ao respeito dos direitos humanos da população refugiada.

Assim, deve-se dar mais atenção, por exemplo, ao direito do estrangeiro de ser assistido por intérprete durante o processo de determinação do status de refugiado. Na prática, apesar de existir previsão legal neste sentido no Brasil, verifica-se que a tradução muitas vezes é precária, feita por refugiado já reconhecido que conhece o idioma do solicitante, estando distante do ideal previsto na Lei. Essa mesma preocupação se aplica à assinatura do Termo de Responsabilidade, após o reconhecimento, uma vez que nesse documento constam informações de extrema relevância ao refugiado que, caso não observadas, podem acarretar a perda do refúgio, como, por exemplo, a necessidade de autorização prévia para viagens ao exterior.

Outra questão reside na fundamentação mencionada na própria Lei $\mathrm{n}^{\circ}$ 9.474/97 que deveria constar da notificação tanto do deferimento quanto do indeferimento do pedido de refúgio. A notificação dada pelo CONARE, em geral, limita-se a indicar que o pedido foi aceito com fundamento no art. $1^{\circ}$ da Lei $n^{\circ}$ 9.474/97 ou que foi indeferido por não se enquadrar nas disposições do mesmo dispositivo ou, mais recentemente, dizer que não há credibilidade ou não há fundado temor de perseguição. Em que pese a necessidade de confidencialidade, esse tipo de fundamentação não permite que o solicitante, quando tenha sua solicitação indeferida, interponha recurso apropriado ao Ministro da Justiça, ou mesmo perante o Judiciário. 
Aliás, nesse particular, uma previsão de possibilidade de acesso ao Poder Judiciário, no que tange à elegibilidade da solicitação de refúgio na Lei no 9.474/97, poderia fazer com que casos de indeferimento pudessem ser analisados pelo Poder Judiciário com mais frequência, visto que a população refugiada desconhece o ordenamento jurídico brasileiro e, em especial, a previsão constitucional do art. $5, \mathrm{XXV}$ da $\mathrm{CF} / 88$, que a todos garante o acesso à justiça ${ }^{40}$. Além disso, fomentaria a reflexão entre os juristas a respeito da coerência entre as normas protetivas de refúgio e direitos humanos, permitindo decisões mais justas.

A Lei no 9.474/97 foi genérica ao considerar os solicitantes de refúgio. Assim, não há procedimentos específicos definidos na esfera das normas de refúgio para casos em que os solicitantes sejam menores, idosos, doentes mentais, deficientes, vítimas de tortura, tratamento cruel ou desumano, entre outras situações de maior vulnerabilidade. Esse descompasso com a tendência de especificação dos sujeitos de direitos humanos não seria uma falha da legislação se todo o procedimento fosse orientado por uma abordagem integral de proteção, guiada pelas

40 "No que tange à jurisprudência brasileira verifica-se que a mesma é escassa no que concerne ao tema dos refugiados, existindo apenas 18 julgados sobre a questão. Nos julgados do Supremo Tribunal Federal, os casos têm natureza variada: 1) há um caso que versa sobre decisão negativa no procedimento de determinação do status de refugiado - Mandado de Segurança 24304/DF de 04/09/2002 -; 2) dois casos que versam sobre pedido de vedação de expulsão em função da pessoa a ser refugiada - Habeas Corpus 69268/ DF de 22/05/1992 e Habeas Corpus 71935/SC de 27/10/1994-; 3) nove casos que versam sobre pedido de vedação de extradição alegando a condição de refugiada da pessoa a ser extraditada - Extradição 232 de 09/10/1961, Extradição 419/ES de 24/04/1985, Extradição 524/PG de 31/10/1990, Habeas Corpus 81176/AL de 08/11/2001, Segunda questão de ordem em extradição 785/ME de 13/09/2001, Reclamação 2069/DF de 27/06/2002, Agravo Regimental nos autos apartados da Extradição 783/ ME de 26/06/2002, Habeas Corpus 83501/DF de 29/10/2003, Embargos Declaratórios na Extradição 785/ME de 27/3/2003-; 4) e três casos que tratam de relaxamento da prisão para extradição quando é feita solicitação de refúgio - Habeas Corpus 81127/DF de 28/11/2001, Segunda questão de ordem em extradição 783/ME de 28/11/2001, Segunda questão de ordem em extradição 784/ ME de 28/11/2001. Os julgados do Superior Tribunal de Justiça são em número de três (Agravo Regimental do Mandado de Segurança 12212/DF; Habeas corpus 36033/DF; e Habeas corpus $32622 / \mathrm{DF}$ ), e denotam por um lado o desconhecimento do tema dos refugiados (ao se referirem ao pedido de reconhecimento como refugiado como sendo um pedido de reconhecimento como "foragido" ou ao se referirem à lei brasileira a respeito de refugiados como sendo a Lei $\mathrm{n}^{\circ} 4.947 / 97$, quando o correto é Lei $\mathrm{n}^{\circ}$ 9.474/97) e por outro lado a tendência de ir sempre a favor das decisões do Comitê Nacional para Refugiados [CONARE] ainda quando verificam que a motivação para a negativa do reconhecimento do status de refugiado é "lacônica"'. Cf. JUBILUT, 2007, p. 102-103, 195. 
obrigações internacionais previstas em instrumentos internacionais universais e regionais a respeito da proteção específica no caso: das mulheres; das crianças em geral e envolvidas no conflito armado; das vítimas de tortura; de tratamento cruel e desumano; e de deficientes.

Para garantir o respeito aos direitos humanos das pessoas acima mencionadas, é fundamental que a Defensoria Pública seja envolvida no processo, de modo a facilitar junto ao Poder Judiciário as medidas necessárias, para garantir a representação do menor, do idoso, dos doentes mentais, quando for o caso. Faz-se necessário ainda começar a se explorar as possibilidades de reparações perante os Estados que infligiram as violações, quando isso não colocar em risco a integridade da própria população refugiada. Esse envolvimento da Defensoria Pública concederá corpo ao art. 16 da Convenção de 51, quando estabelece que o refugiado tenha livre e fácil acesso aos tribunais, gozando do mesmo tratamento de um nacional no que concerne ao acesso aos tribunais, inclusive à assistência judiciária e à isenção de cautio judicatum solvi.

Verifica-se, assim, que uma vez que os padrões mínimos do Direito Internacional dos Refugiados encontram-se presentes na proteção da população refugiada no Brasil em termos de determinação do status de refugiado, deve-se dar o próximo passo e incorporar os desafios que os direitos humanos trazem ao se buscar uma interpretação holística da Proteção Internacional da Pessoa Humana, a fim de se chegar cada vez mais perto de uma proteção integral à população refugiada no país.

\subsection{A proteção da população refugiada na esfera dos direitos econômicos, sociais e culturais}

A relação entre os direitos econômicos, sociais e culturais e a população refugiada pode ser analisada a partir de quatro perspectivas: 1) a violação desses direitos como motivação para a busca de proteção por meio do refúgio ${ }^{41}$; 2) a violação dos referidos direitos durante o deslocamento; 3 ) a proteção da população refugiada nos países de refúgio; e 4) a violação desses direitos a partir do momento

\footnotetext{
${ }^{41}$ A respeito desta perspectiva, cf. FOSTER, 2007.
} 
em que os refugiados retornam a seu país de origem. Importa a este artigo a terceira perspectiva, ou seja, como tem se dado a proteção dos direitos econômicos, sociais e culturais da população refugiada no Brasil.

A princípio, cumpre ressaltar que os direitos humanos não são somente direitos de cidadãos ou nacionais. Os refugiados também têm direito a proteções oferecidas pelo Direito Internacional dos Direitos Humanos, incluindo os direitos econômicos, sociais e culturais. O caput do art. $5^{\circ}$ da CF/88 afirma que todos são iguais perante a lei, sem distinção de qualquer natureza, garantindo-se aos brasileiros e aos estrangeiros residentes no país a inviolabilidade do direito à vida, à liberdade, à igualdade, à segurança e à propriedade. Assim, o regime jurídico constitucional brasileiro protege tanto os brasileiros quanto os estrangeiros.

Além disso, o Supremo Tribunal Federal confirmou a interpretação de que, a teor do disposto no caput do art. 5\%, os estrangeiros residentes no País têm jus aos direitos e garantias fundamentais ${ }^{42}$. A população refugiada tem direito, assim como todas as pessoas, a um padrão de vida, alimentação e moradia adequadas, assim como saúde física e mental.

A Convenção de 51 contém algumas disposições, ainda que limitadas, relacionadas aos direitos econômicos, sociais e culturais ${ }^{43}$. Desse modo, a proteção desses direitos não é apenas uma questão de assistência humanitária, mas uma obrigação internacional assumida pelo Estado que ratificou aquele instrumento internacional e que está obrigado, constitucionalmente, a garantir os direitos humanos também aos estrangeiros residentes em território brasileiro.

O art. 7 da Convenção de 51 inicia estabelecendo que "ressalvadas as disposições mais favoráveis previstas por esta Convenção, um Estado contratante concederá aos refugiados o regime que concede aos estrangeiros em geral". Assim, a maioria das disposições relativas a direitos econômicos, sociais e culturais na

${ }^{42}$ Cf. BRASIL, 1996.

${ }^{43}$ Perante o Direito Internacional, uma pessoa é considerada um refugiado simplesmente em virtude de satisfazer a definição prevista na Convenção de 51, independentemente do processo doméstico de determinação da situação de refugiado. Mas, na prática, verifica-se que os refugiados podem não conseguir ter acesso aos direitos previstos na convenção até que tenham sido formalmente classificados como refugiados pelas autoridades domesticas. As autoridades domésticas em geral consideram que os solicitantes de refúgio não têm direito a proteções especificas da Convenção de 51 . 
Convenção de 51 estabelece que o Estado-membro deve conceder aos refugiados o "tratamento mais favorável" concedido aos nacionais de um país estrangeiro, "nas mesmas circunstâncias" ${ }^{44}$. O capítulo III da Convenção tratou dos empregos remunerados, incluindo as profissões assalariadas ${ }^{45}$, as profissões não assalariadas ${ }^{46} \mathrm{e}$ as profissões liberais ${ }^{47}$.

Aqueles refugiados que conseguem obter um emprego devem se beneficiar, nos termos da Convenção de 51, do mesmo tratamento reservado aos nacionais no que respeita a remuneração e demais direitos relacionados ao trabalho, assim como a respeito de seguridade social, observadas as restrições elencadas no art. 24. A liberdade de associação sem fins políticos nem lucrativos, e relacionada aos sindicatos profissionais foi garantida no art. 15 da Convenção 51, sendo concedido o "tratamento mais favorável".

No Brasil, como visto, o direito ao trabalho é garantido à população refugiada, e os direitos advindos de uma relação de emprego e relativos à seguridade social também o são. Contudo, na prática, a população refugiada enfrenta problemas para, de fato, trabalhar, seja pela dificuldade com o idioma, seja pela falta de experiência ou impossibilidade de sua comprovação, seja pela falta de qualificação,

${ }^{44} \mathrm{O}$ art. 6 da Convenção de 51 explica que a expressão "nas mesmas circunstâncias" implica que todas as condições que o interessado teria que satisfazer para poder exercer o direito em causa, se ele não fosse refugiado, devem ser preenchidas por ele, com exceção das condições que, em razão da sua natureza, não podem ser preenchidas por um refugiado.

${ }^{45} \mathrm{O}$ art. 17, b da Convenção de 51 estipulou que as medidas restritivas impostas aos estrangeiros ou ao emprego de estrangeiros para a proteção do mercado nacional de trabalho, não serão aplicáveis aos refugiados que preencham uma das seguintes condições: i) ter três anos de residência no país; ii) ter por cônjuge uma pessoa que possua a nacionalidade do pais de residência; iii) ter um ou vários filhos que possuam a nacionalidade do pais de residência; iv) os Estados-membros considerarão com benevolência a adoção de medidas tendentes a assimilar os direitos de todos os refugiados, no que concerne ao exercício das profissões assalariadas aos de seus nacionais e, em particular, para os refugiados que entraram no seu território em virtude de um programa de recrutamento de mão de obra ou de um plano de imigração.

${ }^{46} \mathrm{O}$ art. 18 da Convenção de 51 estabelece o "tratamento mais favorável” no que concerne ao exercício de uma profissão não assalariada na agricultura, indústria, artesanato, comércio, bem como à instalação de firmas comerciais e industriais.

${ }^{47} \mathrm{O}$ art. 19 da Convenção de 51 estabeleceu o "tratamento mais favorável” aos refugiados que residam regularmente em seu território e sejam titulares de diplomas reconhecidos pelas autoridades competentes do Estado de refúgio e que desejam exercer uma profissão liberal. 
seja pela discriminação social ${ }^{48}$ ou impossibilidade de exercer a profissão original desempenhada no país de origem, por não poder comprovar mediante apresentação de documentos a sua formação ou pela dificuldade relacionada ao idioma em obter sucesso em exames de habilitação, não obstante as disposições dos artigos 43 e 44 da Lei no 9.474/97. Cenário esse que se agrava com o impacto da crise financeira internacional nos índices de desemprego.

A Convenção de 51 continua dispondo que o mesmo tratamento conferido aos nacionais deve ser dado aos refugiados no caso de existir algum sistema de racionamento de produtos em escassez (art. 20), no que concerne ao ensino primário (art. 22, 1), e em matéria de assistência e de socorros públicos (art. 23). O tratamento tão favorável quanto possível e, em todo caso, não menos favorável do que o que é dado, nas mesmas circunstâncias, aos estrangeiros em geral, deve ser conferido ao refugiado no que concerne a alojamento submetido ao controle das autoridades públicas ou regulado por leis ou regulamento (art. 21); assim como no que concerne à educação, além do ensino primário e, notadamente no que concerne ao acesso aos estudos, ao reconhecimento de certificados de estudos, de diplomas e títulos universitários estrangeiros, à isenção de direitos e taxas e à concessão de bolsas de estudo (art. 22, 2).

A Convenção de 51 não contém disposições a respeito do padrão adequado de vida ou saúde física e mental, e não contém disposições mandatórias claras a respeito do papel da família. Todavia, não se podem esquecer os outros instrumentos internacionais em âmbito universal, tal como, por exemplo, o Pacto Internacional de Direitos Econômicos, Sociais e Culturais, e em âmbito regional o Protocolo de San Salvador, pautados no princípio da não discriminação.

\footnotetext{
${ }^{48}$ A emissão da carteira de trabalho foi regulada pela Resolução do CONARE 7, de 6 de agosto de 2002, e pelo Oficio Circular 103/2006 (CIRP/CGSAP/DES/SPPE/MTE). O Ministério de Trabalho procurou afastar a discriminação por parte do mercado de trabalho e determinou a não utilização da nomenclatura "refugiado" na identificação da documentação laboral. Cf. BARBOSA; HORA, 2007, p. 60.
} 
No ordenamento jurídico brasileiro, a educação é um direito de todos ${ }^{49}$, portanto, de toda a população refugiada. Mas, algumas crianças, em razão da ausência de documentos, como a Certidão de Nascimento ou seu equivalente, enfrentam problemas no acesso a creches e a escolas, demandando a intervenção do Judiciário para o exercício dos direitos garantidos constitucionalmente. No que se refere ao ensino universitário, não há uma política pública consistente, dependendo de decisões pontuais de determinadas instituições de ensino.

No Brasil, a assistência social tem como escopo prover o atendimento a necessidades básicas no que concerne à proteção da família, à maternidade, à infância, à adolescência, à velhice e à pessoa portadora de deficiência, independentemente de contribuição à seguridade social. Seu fundamento é a solidariedade humana, que tem no Estado um instrumento de atuação, objetivando o amparo à pessoa destituída de meios para sobreviver com dignidade.

Em razão das causas de sua fuga, do caráter involuntário do deslocamento e, na maioria das vezes, das dificuldades do percurso, momento em que está completamente vulnerável, o estrangeiro em geral chega ao país no qual busca refúgio traumatizado, carente de tratamento médico, sem recursos financeiros ou outros meios de subsistência. Em razão da situação que motivou a fuga, pode ter se perdido ou sido forçadamente separado de seus familiares ou comunidade de suporte, o que, ademais de significar um trauma emocional, pode também ser a perda do mantenedor. Em geral, não fala o idioma do país de refúgio e pode também enfrentar hostilidade dos residentes no país advinda de discriminação racial ou outra. Desse modo, necessita do amparo da assistência social.

O art. 203 da CF/88 determina consoante segue:

A assistência social será prestada a quem dela necessitar, independentemente de contribuição à seguridade social, e tem por objetivos:

I - a proteção à família, à maternidade, à infância, à adolescência e à velhice;

\footnotetext{
${ }^{49}$ Nos termos do art. 205 da CF/88, a educação é direito de todos e dever do Estado e da família, devendo ser promovida e incentivada com a colaboração da sociedade, visando ao pleno desenvolvimento da pessoa, seu preparo para o exercício da cidadania e sua qualificação para o trabalho.
} 
II - o amparo às crianças e aos adolescentes carentes;

III - a promoção da integração ao mercado de trabalho;

IV - a habilitação e reabilitação das pessoas portadoras de deficiência e a promoção de sua integração à vida comunitária;

V - a garantia de um salário mínimo de benefício mensal à pessoa portadora de deficiência e ao idoso que comprovem não possuir meios de prover à própria manutenção ou de tê-la provida por sua família, conforme dispuser a lei.

Desse modo, ao mencionar que será prestada a quem dela necessitar não excluiu os estrangeiros, muito menos os refugiados.

No que se refere ao direito à saúde, na medida em que a saúde no Brasil é direito de $\operatorname{todos}^{50}$, o que é demandado são políticas de facilitação do acesso a um sistema que é universal. Ações pontuais submetidas à vontade política e muitas vezes devidas a pessoas solidárias atuantes nas instituições podem ser identificadas, mas não conferem garantia alguma de continuidade, caso haja uma mudança política ou caso a pessoa seja transferida da instituição ou mesmo do cargo por ela ocupado.

Este é o caso da criação do que foi denominado Centro de Referência para a Saúde dos Refugiados, no Hospital dos Servidores do Estado do Rio de Janeiro. Não há nenhum instrumento legal criando tal Centro de Referência, nem determinando políticas de treinamento dos funcionários da área de saúde. Tais iniciativas se devem ao esforço de pessoas envolvidas no âmbito da instituição e da sociedade civil. Não obstante, o risco de descontinuidade contribui para indicar o caminho para a entrada no sistema de saúde à população refugiada, o qual não é vedado a nenhum estrangeiro, de acordo com os termos constitucionais.

A população refugiada não é um grupo homogêneo, do que decorre que podem ter diferentes experiências práticas e problemas variados nos países de refúgio. Angolanos, congoleses, colombianos, iraquianos, afegãos etc. com certeza enfrentam situações diferenciadas no dia a dia no Brasil. Contudo, há um problema

${ }^{50} \mathrm{O}$ art. 196 da CF/88 reconhece que a saúde é direito de todos e dever do Estado, garantido mediante políticas sociais e econômicas que visem à redução do risco de doença e de outros agravos e ao acesso universal e igualitário às ações e aos serviços para sua promoção, proteção e recuperação. 
comum que é compartilhado por todos, independentemente de sua nacionalidade, de sua origem social ou de qualquer outro critério - a população refugiada enfrenta problemas práticos para realizar os direitos econômicos, sociais e culturais dos quais é titular.

No Brasil, não há campos de refugiados, caso em que haveria de se falar em toda uma logística para a realização dos direitos humanos. Há sim, como visto, um procedimento que demanda certo tempo para se obter o reconhecimento do status de refugiado, necessidade de obter os documentos que permitem a estada e o exercício do direito ao trabalho, necessidade de aprender o caminho do acesso aos benefícios que pode ter direito por ser parte da população refugiada e também simplesmente por ser humano. Todos esses desafios são dificultados pelo desconhecimento do idioma e por outras dificuldades de integração que podem variar desde a discriminação por parte da comunidade do país de refúgio, os traumas sofridos e suas sequelas, até o desconhecimento dos agentes do Estado de que aquele estrangeiro tem direito a ter direitos, e, em algumas circunstâncias, tem direitos específicos.

É importante ressaltar que a interpretação atual dos direitos econômicos, sociais e culturais da população refugiada adota como padrão de análise da integração a situação do país de origem, ou seja, não se propugna por um tratamento diferenciado ou melhor para os refugiados do que para os nacionais, mas sim, um tratamento igualitário como previsto na Convenção de 51.

Tendo em vista, assim, a realidade normativa e a prática, verifica-se que é necessária a implementação de políticas públicas que permitam a efetiva realização dos direitos econômicos, sociais e culturais da população refugiada, seja por sua inclusão em políticas já existentes, seja pela adequação de políticas que permitam a inclusão dessa população ou pela criação de novas políticas.

Essa preocupação, que já vinha sendo debatida na doutrina ${ }^{51}$, está ganhando espaço na atuação governamental. Tem-se verificado iniciativas do CONARE de sensibilizar outros órgãos federais no sentido de que as obrigações internacionais do Brasil em relação à população refugiada sejam integralmente cumpridas e que, assim, sejam assegurados os seus direitos econômicos, sociais e culturais.

\footnotetext{
${ }^{51}$ Cf., por exemplo, MILESE; AMBROS, 2007.
} 
O mesmo papel de sensibilização vem sendo desempenhado pelo ACNUR e pela sociedade civil, com destaque para o trabalho realizado em São Paulo. Em menos de um ano foram estabelecidos o Comitê Estadual para Refugiados (CER) ${ }^{52}$ e o Comitê Paulista para Imigrantes e Refugiados ${ }^{53}$, com o propósito de facilitar a integração dos refugiados e, consequentemente, de assegurar políticas públicas que garantam os direitos econômicos, sociais e culturais da população refugiada.

Essas iniciativas demonstram que, gradativamente, o Brasil caminha no sentido da proteção integral à população refugiada e que, ainda que se esteja longe do ideal, pelo menos parece haver um despertar governamental para o tema e um desejo de aprofundar a proteção e a acolhida da população refugiada no Brasil. Há necessidade de uma ação concertada entre as instituições governamentais e a sociedade civil, elevando em conta as obrigações assumidas internacionalmente pelo Estado brasileiro no que respeita à proteção internacional da pessoa humana.

\section{Conclusão}

A busca da proteção integral da população refugiada é um desafio que deve ser enfrentado caso se queira assegurar a proteção plena da dignidade inerente a todos os seres humanos. É um processo contínuo de análise e busca de aprimoramento que tem maiores chances de ser efetivada quando a acolhida e a proteção englobam o governo, a comunidade internacional e a sociedade civil.

Nesse sentido, o Brasil parece caminhar na direção certa, o mesmo acontecendo com as recentes iniciativas de debate e criação de políticas públicas que envolvam ou que sejam específicas para a população refugiada.

Apesar disso, os avanços são ainda tímidos em termos de resultados concretos o que pode ser explicado: (i) pelo pequeno número de refugiados e solicitantes

${ }^{52}$ O CER, estabelecido em $1^{\circ}$ de abril de 2008, é um órgão do governo do Estado de São Paulo, composto por representantes de secretarias estaduais e das Cáritas Arquidiocesana de São Paulo e Brasileira Regional São Paulo, que visa a propor e implementar políticas públicas que auxiliem a integração da população refugiada em São Paulo.

${ }^{53} \mathrm{O}$ Comitê Paulista para Imigrantes e Refugiados foi estabelecido em 5 de fevereiro de 2009 e tem como objetivo congregar e juntar esforços entre Poder Público e Sociedade Civil para a informação, a proposição e a implementação de Políticas Públicas voltadas para populações vulneráveis de refugiados e imigrantes na cidade de São Paulo. 
de refúgio no Brasil; (ii) pelo fato de o sistema de acolhida e proteção à população refugiada atual ser uma criação não tão antiga; (iii) pelo fato de a preocupação do Brasil em respeitar as normas internacionais de proteção de a pessoa humana ser algo recente em nossa história; (iv) pelo distanciamento do Judiciário em face à questão do refúgio e dificuldade de busca de garantias para o respeito aos direitos dos refugiados; e (v) pelo eterno problema da vontade política em assegurar direitos sem que haja um retorno em termos de interesses e ganhos diretos.

Vê-se, assim, que o Brasil deu passos significativos, contudo, enfrenta ainda grandes desafios na busca de assegurar uma proteção integral à população refugiada. Faz-se necessário fomentar decisões, políticas e as ações que apontam para a direção adequada, ou seja, no sentido da maior proteção possível a pessoas que só podem contar com a solidariedade e a cooperação internacionais.

\section{The refugee population in Brazil: the search for a comprehensive protection}

\section{Abstract}

Brazil is generally pointed as a model of protection to refugee population in South America, what seems reasonable if the minimum standards of the International Refugee Law are considered. However, there are still challenges to be faced in order to provide a comprehensive protection that encompasses also standards established by the International Human Rights Law. This article intends to present which are the challenges to an effective holistic protection of the human dignity of the refugee population.

Keywords: Refugee population. Refugee. Brazil. Human rights. Protection. Comprehensive protection.

\section{Referências}

ACNUR. Plan de acción de México. Geneva, 2009. Disponível em: <http://www. acnur.org/pam/>. Acesso em: 29 jun. 2009.

APOLINÁRIO, Silvia Menicucci O. S.; JUBILUT, Liliana L. Refugee status determination in Brazil: a tripartite enterprise.[S.1.]: Refuge, Mar. 2009. (Mimeo). 
BRASIL. Constituição (1988). Constituição da República Federativa do Brasil. Disponível em: <http://www.planalto.gov.br/ccivil_03/constituicao/ constitui\%C3\%A7ao.htm>. Acesso em: 29 jun. 2009.

BRASIL. Lei $n^{\circ}$ 6.815, de 19 de julho de 1980. Define a situação jurídica do estrangeiro no Brasil, cria o Conselho Nacional de Imigração. Disponível em: $<$ http://www.planalto.gov.br/CCIVIL/LEIS/L6815.htm>. Acesso em: 26 jun. 2009.

BRASIL. Lei $n^{\circ}$ 9.474, de 22 de julho de 1997. Define mecanismos para a implementação do Estatuto dos Refugiados de 1951, e determina outras providências. Brasília, 1997. Disponível em: <http://www.planalto.gov.br/CCIVIL/ LEIS/L9474.htm>. Acesso em: 26 jun. 2009.

BRASIL. Superior Tribunal de Justiça. Processo Penal. Habeas-corpus. Direitos e garantias fundamentais do estrangeiro. Habeas-corpus $n^{\circ} 74.051$ do Tribunal Regional Federal do Estado de Santa Catarina, Brasília, DF, 18 de junho de 1996. Disponível em: < http://www.stf.jus.br/portal/processo/ verProcessoAndamento. asp? numero $=74051 \&$ classe $=\mathrm{HC} \&$ codigoClasse $=0$ \&origem $=\mathrm{AP} \&$ recurso $=0$ \&tipo Julgamento $=\mathrm{M}>$. Acesso em: 29 jun. 2009.

BRASIL. Supremo Tribunal Federal. Acórdão. Extradição: Colômbia: crimes relacionados à participação do extraditando - então sacerdote da Igreja Católica - em ação militar das Forças Armadas Revolucionárias da Colômbia (FARC). Questão de ordem... Ext 1008 / CB - COLÔMBIA. Tribunal Pleno. Relator(a): Min. Gilmar Mendes. Relator(a) p/ Acórdão: Min. Sepúlveda Pertence. Brasília, 21 mar. 2007. Disponível em: <http://www.stf.jus.br/ portal/jurisprudencia/listarJurisprudencia. asp?s1=Ext.SCLA.\%20E\%201008.NUME.\&base=baseAcordaos $>$. Acesso em: 29 jun. 2009.

BRASIL. Supremo Tribunal Federal. Acórdão. Extradição. Questão de ordem. Pedido de refúgio. Suspensão do processo. Lei no 9.474/97, art. 34. Questão de ordem resolvida no sentido de que o pedido de refúgio, formulado após o julgamento de mérito da extradição, produz o efeito de suspender o processo, mesmo quando já publicado o acórdão, impedindo o transcurso do prazo recursal. Ext 785 QO-QO / ME - MÉXICO. Tribunal Pleno. Relator(a): Min. Néri da Silveira. Brasília, 13 set. 2001. Disponível em: <http://www.stf.jus.br/portal/ jurisprudencia/listarJurisprudencia.asp?s1 = Ext-QO-QO.SCLA.\%20E\%20785. NUME.\&base $=$ baseAcordaos $>$. Acesso em: 29 jun. 2009.

CONVENÇÃO de 1951 relativa ao Estatuto dos Refugiados. Disponível em: $<$ http://www.cidadevirtual.pt/acnur/refworld/refworld/legal/instrume/asylum/ conv-0.html $>$. Acesso em: 29 jun. 2009. 
FISCHEL DE ANDRADE, H. H; MARCOLINI, A. A política brasileira de proteção e reassentamento de refugiados: breves comentários sobre suas principais características, Revista Brasileira de Política Internacional, [S.l.], v. 45, n. 1, p. 168176, 2002.

JUBILUT, Liliana L. O direito internacional dos refugiados e sua aplicação no ordenamento jurídico brasileiro. São Paulo: Método, 2007.

JUBILUT, Liliana L. O procedimento de concessão de refúgio no Brasil. Disponível em: <http://www.mj.gov.br/data/Pages/MJ7605B707ITEMIDA5 DA279AA51B46539284ED27C62FF31APTBRIE.htm>. Acesso em: 26 jun. 2009.

LAFER, C. A reconstrução dos direitos humanos: um diálogo com o pensamento de Hannah Arendt. 3. reimp. São Paulo: Companhia das Letras, 1999.

NOGUEIRA, Maria Beatriz; MARQUES, Carla Cristina. Brazil: ten years of refugee protection. Forced Migration Review, [S.1.], n. 30, p. 57-58, Apr. 2008. 